\title{
Sleep apnea and unilateral upper and lower extremity allodynia as a result of a large thoracic disc herniation: a case report
}

\author{
Tyler D. Alexander ${ }^{*} \mathbb{D}$, Anthony Stefanelli, Sara Thalheimer and Joshua E. Heller
}

\begin{abstract}
Background: Clinically significant disc herniations in the thoracic spine are rare accounting for approximately $1 \%$ of all disc herniations. In patients with significant spinal cord compression, presenting symptoms typically include ambulatory dysfunction, lower extremity weakness, lower extremity sensory changes, as well as bowl, bladder, or sexual dysfunction. Thoracic disc herniations can also present with thoracic radiculopathy including midback pain and radiating pain wrapping around the chest or abdomen. The association between thoracic disc herniation with cord compression and sleep apnea is not well described.

Case presentation: The following is a case of a young male patient with high grade spinal cord compression at T7-8, as a result of a large thoracic disc herniation. The patient presented with complaints of upper and lower extremity unilateral allodynia and sleep apnea. Diagnosis was only made once the patient manifested more common symptoms of thoracic stenosis including left lower extremity weakness and sexual dysfunction. Following decompression and fusion the patient's allodynia and sleep apnea quickly resolved.
\end{abstract}

Conclusions: Thoracic disc herniations can present atypically with sleep apnea. We recommend taking into consideration that sleep symptoms may resolve when planning treatment for thoracic disc herniation.

Keywords: Thoracic disc herniation, Myelopathy, Sleep apnea, Allodynia

\section{Background}

Symptomatic thoracic disc herniations account for approximately $1 \%$ of all disc hernations with T11-12 most commonly involved (Arce et al. 1985; Arts et al. 2014; Bouthors et al. 2019). The levels T8-12 account for around $75 \%$ of all thoracic disc herniations (Arts et al. 2014; Burns et al. 2000; Burns et al. 2001; Carvalho et al. 2017). Symptomatic thoracic herniations typically presents with leg weakness, paraesthesias, and gait instability (Chiodo et al. 2016). They can also result in bowel and bladder or sexual dysfunction (Chung et al. 2016). Less frequently, thoracic herniations can present with lower

*Correspondence: tda003@jefferson.edu

Department of Neurological Surgery, Thomas Jefferson University

Hospitals, 909 Walnut Street, Third Floor, Philadelphia, PA 19107, USA extremity allodynia (Cornips et al. 2011; Finnerup et al. 2016). Operative treatment for symptomatic thoracic disc herniations includes decompression and possibly instrumented fusion (Bouthors et al. 2019). The approach to thoracic disc depends on location (central vs paracentral) and degree of calcification (Gille et al. 2006). The classic teaching is that central discs should not be approached via laminectomy alone (Hott et al. 2005; Kapur 2010).

At present, there have been no documented cases of thoracic disc herniations presenting as parasomnias. However, various studied have associated other spine pathologies - particularly those in the cervical region with sleep apnea (Khan et al. 2014; Massimiliano et al. 2014; Nguyen et al. 2004). Here, we present an individual with a thoracic disc herniation who developed progressive myelopathic symptoms, upper and lower extremity original author(s) and the source, provide a link to the Creative Commons licence, and indicate if changes were made. The images or other third party material in this article are included in the article's Creative Commons licence, unless indicated otherwise in a credit line to the material. If material is not included in the article's Creative Commons licence and your intended use is not permitted by statutory regulation or exceeds the permitted use, you will need to obtain permission directly from the copyright holder. To view a copy of this licence, visit http://creativecommons.org/licenses/by/4.0/. 
allodynia, and clinically significant sleep apnea. All symptoms improved rapidly following surgical treatment with immediate resolution of the sleep apnea.

\section{Case presentation}

A non-obese $(\mathrm{BMI}=27)$ 30-year-old male initially presented to neurology two years prior to diagnosis with primary complaint of left upper and lower extremity allodynia. The patient initially had left worse than right subtle lower extremity weakness, and ambulatory dysfunction. Additional symptoms included sleep apnea and sexual dysfunction. The patient had imaging of the brain and cervical spine which was normal. The patient's symptoms progressed over time and ultimately the patient was referred to neurosurgery after a thoracic magnetic resonance imaging (MRI) demonstrated a large left paramedian disc herniation at T7-8 (Fig. 1). By time of neurosurgical evaluation, the patient had symptoms of thoracic myelopathy for several years. The patient had left greater than right lower extremity weakness, sexual dysfuncton, and mild bowel and bladder dysfunction.

Approximately six months prior to presentation, the patient was diagnosed with sleep apnea requiring the use of a continuous positive airway pressure device. Based on a score of 3 in the STOP-BANG questionnaire - a validated tool for assessment of risk of sleep apnea the patient was deemed to be high risk (O'Connor et al. 2002). The patient was diagnosed following a sleep study using a polysonography system in which electroencephalography and electromyography were monitored for sleep staging and were coupled with respiratory and cardiac measurements. In it, sleep latency was $80.6 \mathrm{~min}$. Stage $\mathrm{N} 1$ sleep was $3.6 \%$, stage N2 was $61.2 \%$, and stage N3 was $18.3 \%$. There were $22.3 \mathrm{~min}$ of wake after sleep onset with 4 REM sleep periods. Stage R sleep was $16.8 \%$ and latency was $75 \mathrm{~min}$. The overall apnea-hypoxia index was 14.7 events per hour, with a nadir oxygen saturation of $77 \%$. Throughout the study there were 54 obstructive apneas with a mean duration of $25.8 \mathrm{~s}$; the obstructive apnea index was 9.8 events per hour. There were 27 obstructive hypopneas with a mean duration of $26.8 \mathrm{~s}$ and 18 respiratory effort-related arousals resulting in a RERA index of 3.3 events per hour. The respiratory disturbance index was 18 events per hour. There were 59 arousals related to respiratory events with an index of 10.7 arousals per hour and also 23 spontaneous arousals noted as well.

On physical exam, the patient demonstrated significant motor weakness in his proximal lower extremities left worse than right. Patellar reflexes were hyperreflexic $(3+)$ bilaterally. There was an imbalance of tandem gait, as well as allodynia in the upper and lower extremities.

MRI of the thoracic spine demonstrated a large left paracentral T7-8 disc herniation causing significant stenosis. Computed tomography scan showed the disc to be heavily calcified (Fig. 2). It was recommended that the patient undergo operative treatment due to the patient's progressive neurologic decline.

The patient underwent posterior instrumented fusion T6 through T10, including laminectomy left T7-8 costotransversectomy, partial corpectomy and discectomy (Fig. 3). The patient's postoperative course was uneventful. After surgery, the patient reported improvements in sleep, sensation in the upper and lower extremities, and strength in the lower extremities following surgery (Fig. 4).

Following surgery, the patient reported immediate resolution in his sleep symptoms. In the proceeding time, the patient consistently reported improvement. On interviews at one month, three months, and six months postoperatively the patient indicated that his

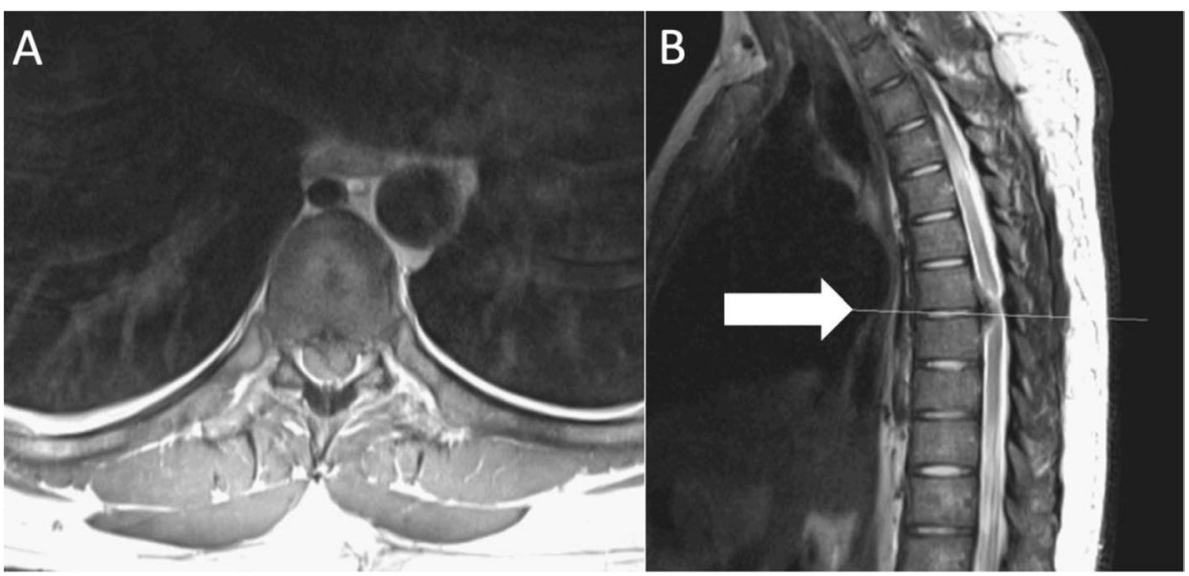

Fig. 1 Preoperative T2 weighted MRI in (A) axial and (B) sagittal views, indicating the level of herniation (arrow) 


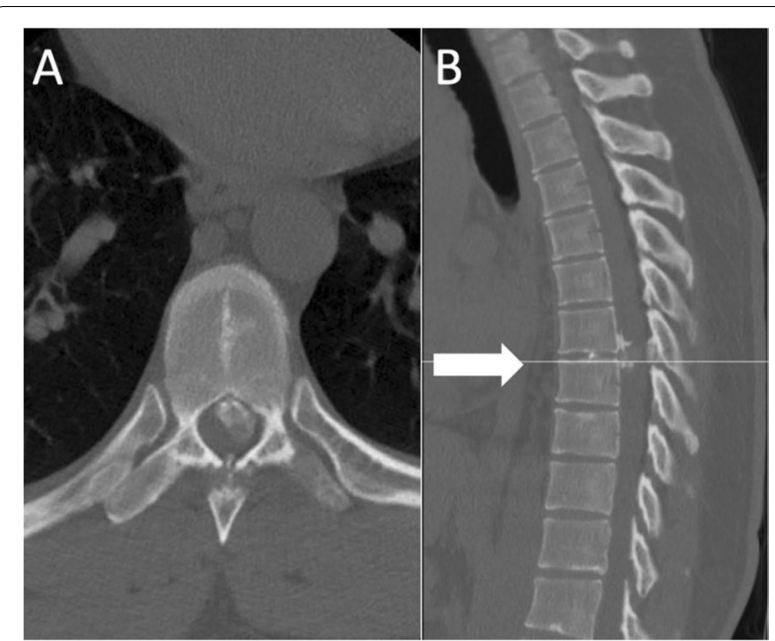

Fig. 2 Preoperative CT images in (A) axial and (B) sagittal views of the herniation at the indicated level

sleep apnea had improved tremendously and that associated sleep symptoms had been resolved. This was a marked change; whereas, for at least one year prior to surgery the patient stated that he had disturbances when sleeping, beginning immediately postoperatively the patient stated that he no longer experienced trouble sleeping nor did he have disturbances.

\section{Discussion and conclusions}

Clinically symptomatic thoracic disc herniations that require surgical intervention are relatively rare and patients typically present with symptoms of thoracic myelopathy or radiculopathy (Chiodo et al. 2016; Okinaga et al. 2005; Onishi et al. 2016). In the case of this patient, a delayed diagnosis was caused by both the atypical presentation of sleep apnea as well as the upper and lower extremity allodynia (Burns et al. 2001). Allodynia has been associated with thoracic disc herniation - though it is less common and when present, typically occurs at the level of the herniation itself (Cornips et al. 2011; Nguyen et al. 2004). In this patient, both upper and lower extremity involvement in allodynia were atypical as was the sleep apnea itself.

We acknowledge that it is difficult to associate direct causality of the resolution of the patient's sleep apnea with his discectomy. It is possible that the resolution of the sleep disturbance was due to the resolution of pain following decompression of the thoracic spinal cord. However, such is unlikely because the patient's obstructive sleep apnea was documented in sleep studies - and less-likely due to symptoms of pain. It is more likely that the sleep apnea and its resolution is related to the disc herniation and treatment.

Sleep apnea is caused by anatomic or partial obstruction of the airway during sleep (Khan et al. 2014; Punjabi and Punjabi 2008). The estimated prevalence of sleep apnea is around 3\% to 7\% (Quint et al. 2012). While studies have associated spinal cord injury with sleep apnea - particularly within the cervical region - there

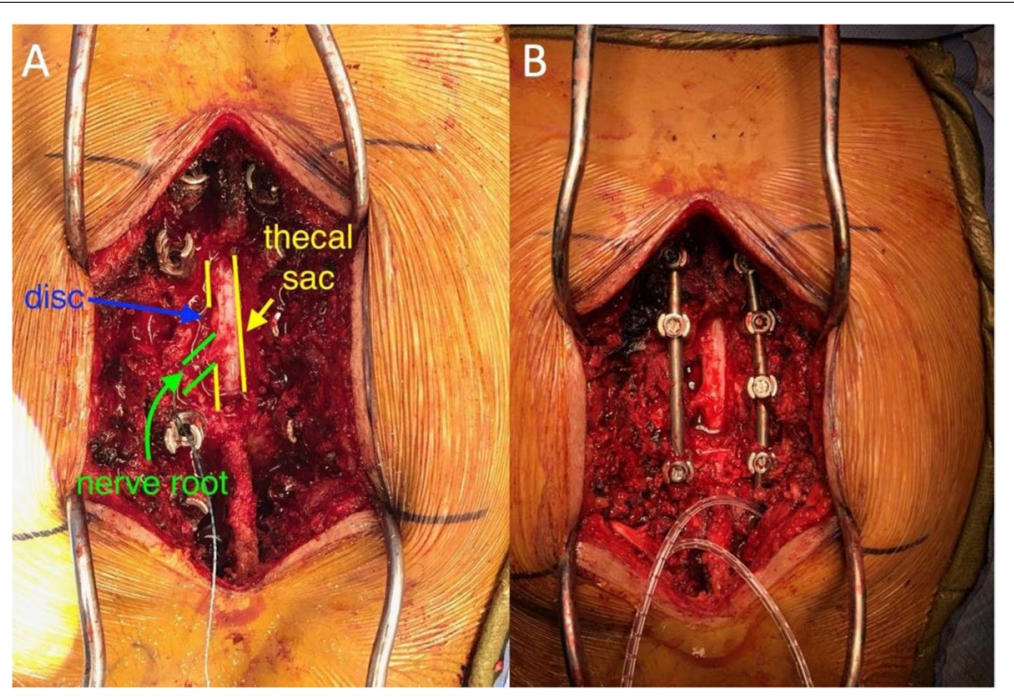

Fig. 3 A Interop photograph demonstrating posterior exposure s/p laminectomy, left T7-T8, T8-9 facetectomy, costotransversectomy, and removal of left T8 pedicle prior to resection of disc herniation. Herniation can be seen causing significant tension on the thecal sac and spinal cord. B Interop photograph following partial corpectomy and discectomy with circumferential decompression of the spinal cord. Instrumentation T6-T10 


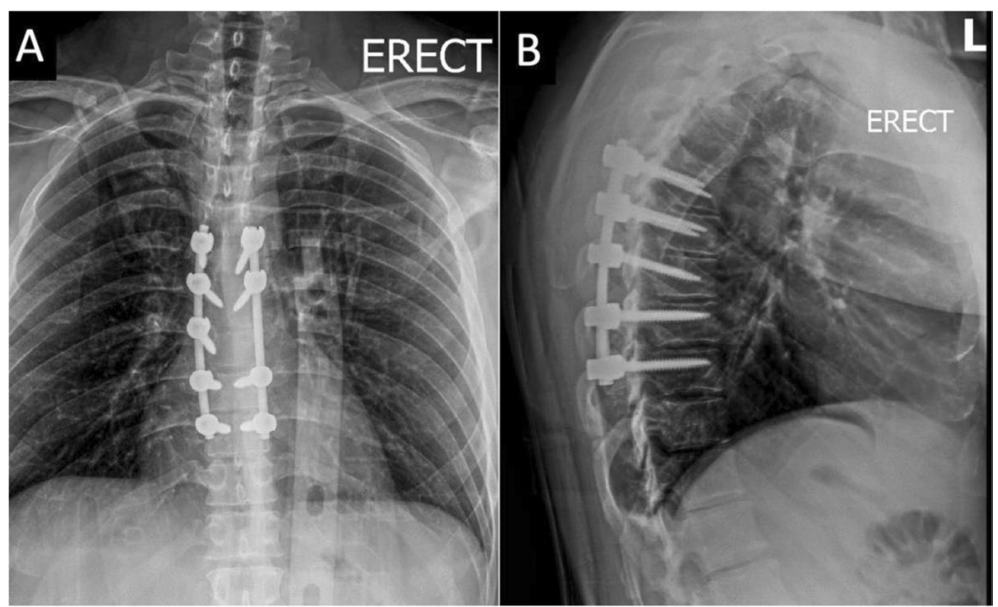

Fig. 4 Postoperative (A) AP and (B) lateral X rays

has been little research about the association of sleep apnea and thoracic disc herniation (Scheer et al. 2006). One documented case reported transient onset of central sleep apnea, following cervical laminectomy (Shirzadi et al. 2013). However, to date, no studies have explored an association between thoracic herniations and such sleep pathology. Because sleep apnea is caused by airway pathology and the thoracic and cervical spinal cord is closely related, it is possible that the relationship between thoracic nerves and chest wall muscles may be involved. $\mathrm{T} 1$ through T11 are associated with chest wall movement and there have been studies associating thoracic spinal cord injury with sleep apnea (Sivakumaran et al. 2018; Sonnesen and Sonnesen 2010; Videman et al. 1995). It is thought that weakness in chest muscles, caused by spinal cord injury, produces symptoms of sleep apnea. Specific to the cervical region, cervical spine-related sleep apnea is caused by injury to neck muscles that affect airway patency - a pathophysiologic relationship which is reversible upon treatment of the cervical pathology (Khan et al. 2014). This phenomenon could be applicable to the thoracic region, too. Possibly, thoracic herniation mimicked pathology similar to that induced by spinal cord injury and chest wall muscle strength - as it relates to sleep apnea; the symptoms of sleep apnea were therefore resolved, following resolution of the pressure from spinal cord injury. Without further case reports and studies, however, we are unsure of whether or not this is the underlying pathophysiologic mechanism behind the resolution of apnea in this case report.

Here we presented the case of a patient with thoracic disc herniation treated surgically. The patient presented with sleep apnea as part of his symptomatology - a complaint that was completely resolved, following treatment of the thoracic HNP alone. We hypothesize that the herniation produced symptoms of sleep apnea, in line with the way thoracic spinal cord injury has produced symptoms of sleep apnea. In the case of the thoracic HNP, because it was treatable surgically, the apnea resolved. Additional work needs to be done, in order to explore this relationship further.

\section{Abbreviation \\ HNP: Disc herniation.}

\section{Acknowledgements \\ Not applicable.}

\section{Authors' contributions}

All authors contributed to the ideas in the report - as well as the drafting, reviewing, and approval of the article.

\section{Funding}

Not applicable.

\section{Availability of data and materials}

Data and materials are not available to be shared publically, due to the nature of this article.

\section{Declarations}

Ethics approval and consent to participate

Ethics approval and consent to participate were approved by the IRB at Thomas Jefferson University.

\section{Consent for publication}

Due to the nature of the study and IRB approval, patients waive consent to publication. IRB and approval waiver are both attached and available.

\section{Competing interests}

Not applicable. 
Received: 23 February 2021 Accepted: 6 September 2021

Published online: 10 November 2021

\section{References}

Arce CA, Dohrmann GJ. Thoracic disc herniation: Improved diagnosis with computed tomographic scanning and a review of the literature. Surg Neurol. 1985;23(4):356-61. https://doi.org/10.1016/0090-3019(85) 90206-X.

Arts MP, Bartels RHMA. Anterior or posterior approach of thoracic disc herniation? A comparative cohort of mini-transthoracic versus transpedicular discectomies. Spine J. 2014;14(8):1654-62.

Bouthors C, Benzakour A, Court C. Surgical treatment of thoracic disc herniation: an overview. Int Orthop. 2019;43(4):807-16. https://doi.org/10.1007/ s00264-018-4224-0.

Burns SP, Little JW, Hussey JD, Lyman P, Lakshminarayanan S. Sleep apnea syndrome in chronic spinal cord injury: associated factors and treatment. Arch Phys Med Rehabil. 2000;81(10):1334-9. https://doi.org/10.1053/ apmr.2000.9398.

Burns SP, Kapur V, Yin KS, Buhrer R. Factors associated with sleep apnea in men with spinal cord injury: a population-based case-control study. Spinal Cord. 2001;39(1):15-22. https://doi.org/10.1038/s.sc.3101103.

Carvalho R, Segura E, do Loureiro MC, Assunção JP. Quadratus lumborum block in chronic pain after abdominal hernia repair: case report. Braz J Anesthesiol (English Ed). 2017;67(1):107-9. https://doi.org/10.1016/j. bjane.2014.08.010.

Chiodo AE, Sitrin RG, Bauman KA. Sleep disordered breathing in spinal cord injury: a systematic review. J Spinal Cord Med. 2016:39(4):374-82. https:// doi.org/10.1080/10790268.2015.1126449.

Chung F, Abdullah HR, Liao P. STOP-bang questionnaire: a practical approach to screen for obstructive sleep apnea. Chest. 2016;149(3):631-8. https:// doi.org/10.1378/chest.15-0903.

Cornips EMJ, JanssEn MLF, Beuls EAM. Thoracic disc herniation and acute myelopathy: clinical presentation, neuroimaging findings, surgical considerations, and outcome. J Neurosurg Spine. 2011;14(4):520-8.

Finnerup NB, Jensen MP, Norrbrink C, et al. A prospective study of pain and psychological functioning following traumatic spinal cord injury. Spinal Cord. 2016;54(10):816-21.

Gille O, Soderlund C, Razafimahandri HJC, Mangione P, Vital J-M. Analysis of hard thoracic herniated discs: review of 18 cases operated by thoracoscopy. Eur Spine J. 2006;15(5):537-42.

Hott JS, Feiz-Erfan I, Kenny K, Dickman CA. Surgical management of giant herniated thoracic discs: analysis of 20 cases. J Neurosurg Spine. 2005;3(3):191-7.

Kapur VK. Obstructive sleep apnea: diagnosis, epidemiology, and economics. Respir Care. 2010;55(9):1155 LP - 1167 (http://rc.rcjournal.com/content/ 55/9/1155.abstract).

Khan A, Than KD, Chen KS, Wang AC, La Marca F, Park P. Sleep apnea and cervical spine pathology. Eur Spine J off Publ Eur Spine Soc Eur Spinal Deform
Soc Eur Sect Cerv Spine Res Soc. 2014;23(3):641-7. https://doi.org/10. 1007/s00586-013-3046-4.

Massimiliano V, Della Pepa GM, Giuseppe B, Aldo S. Reversible and delayed isolated central sleep apnea after cervical laminectomy: report of the first case. Acta Neurochir (wien). 2014;156(2):267-8. https://doi.org/10.1007/ s00701-013-1904-9.

Nguyen HV, Ludwig SC, Silber J, et al. Rheumatoid arthritis of the cervical spine. Spine J. 2004;4(3):329-34. https://doi.org/10.1016/j.spinee.2003. 10.006

O'Connor RC, Andary MT, Russo RB, DeLano M. Thoracic radiculopathy. Phys Med Rehabil Clin. 2002;13(3):623-44

Okinaga H, Matsuno A, Okazaki R. High risk of osteopenia and bone derangement in postsurgical patients with craniopharyngiomas, pituitary adenomas and other parasellar lesions. Endocr J. 2005;52(6):751-6. https://doi. org/10.1507/endocr.52.751.

Onishi E, Yasuda T, Yamamoto H, Iwaki K, Ota S. Outcomes of surgical treatment for thoracic myelopathy: a single-institutional study of 73 patients. Spine (Phila Pa 1976). 2016;41 (22):E1356-63.

Punjabi NM. The epidemiology of adult obstructive sleep apnea. Proc Am Thorac Soc. 2008:5(2):136-43. https://doi.org/10.1513/pats. 200709-155MG

Quint U, Bordon G, Preissl I, Sanner C, Rosenthal D. Thoracoscopic treatment for single level symptomatic thoracic disc herniation: a prospective followed cohort study in a group of 167 consecutive cases. Eur Spine J. 2012;21(4):637-45.

Scheer FAJL, Zeitzer JM, Ayas NT, Brown R, Czeisler CA, Shea SA. Reduced sleep efficiency in cervical spinal cord injury; association with abolished night time melatonin secretion. Spinal Cord. 2006;44(2):78-81. https://doi.org/ 10.1038/sj.sc.3101784

Shirzadi A, Drazin D, Jeswani S, Lovely L, Liu J. Atypical presentation of thoracic disc herniation: case series and review of the literature. Tsurumoto $T$, Madrazo I, eds. Case Rep Orthop. 2013;2013:621476. https://doi.org/10. 1155/2013/621476.

Sivakumaran R, Uschold TD, Brown MT, Patel NR. Transfacet and transpedicular posterior approaches to thoracic disc herniations: consecutive case series of 24 patients. World Neurosurg. 2018;120:e921-31. https://doi.org/10. 1016/j.wneu.2018.08.191

Sonnesen L. Associations between the cervical vertebral column and craniofacial morphology. Int J Dent. 2010;2010: 295728. https://doi.org/10. 1155/2010/295728.

Videman T, Battié MC, Gill K, Manninen H, Gibbons LE, Fisher LD. Magnetic resonance imaging findings and their relationships in the thoracic and lumbar spine. Insights into the etiopathogenesis of spinal degeneration. Spine (Phila Pa 1976). 1995;20(8):928-35.

\section{Publisher's Note}

Springer Nature remains neutral with regard to jurisdictional claims in published maps and institutional affiliations.

Ready to submit your research? Choose BMC and benefit from:

- fast, convenient online submission

- thorough peer review by experienced researchers in your field

- rapid publication on acceptance

- support for research data, including large and complex data types

- gold Open Access which fosters wider collaboration and increased citations

- maximum visibility for your research: over $100 \mathrm{M}$ website views per year

At $\mathrm{BMC}$, research is always in progress.

Learn more biomedcentral.com/submissions 